\title{
Triol-promoted activation of C-F bonds: Amination of benzylic fluorides under highly concentrated conditions mediated by 1,1,1-tris(hydroxymethyl)propane
}

Pier Alexandre Champagne, Alexandre Saint-Martin, Mélina Drouin and Jean-François Paquin*

\author{
Letter \\ Address: \\ Canada Research Chair in Organic and Medicinal Chemistry, CCVC, \\ PROTEO, Département de chimie, Université Laval, 1045 avenue de \\ la Médecine, Québec, QC, Canada G1V OA6 \\ Email: \\ Jean-François Paquin * jean-francois.paquin@chm.ulaval.ca \\ * Corresponding author \\ Keywords: \\ C-F bond activation; highly concentrated conditions; nucleophilic \\ substitution; hydrogen bond; organofluorine; triol
}

\author{
Beilstein J. Org. Chem. 2013, 9, 2451-2456. \\ doi:10.3762/bjoc. 9.283 \\ Received: 27 August 2013 \\ Accepted: 17 October 2013 \\ Published: 13 November 2013 \\ This article is part of the Thematic Series "Organo-fluorine chemistry III". \\ Guest Editor: D. O'Hagan
}

(c) 2013 Champagne et al; licensee Beilstein-Institut.

License and terms: see end of document.

\begin{abstract}
Activation of the C-F bond of benzylic fluorides was achieved using 1,1,1-tris(hydroxymethyl)propane (2) as a hydrogen bonddonating agent. Investigations demonstrated that hydrogen bond-donating solvents are promoting the activation and hydrogen bondaccepting ones are hindering it. However, the reaction is best run under highly concentrated conditions, where solvents cannot interfere with the interaction between the organofluorine compound and the triol. Various benzylic fluorides react with secondary amines or anilines to form benzylic amines in good yields.
\end{abstract}

\section{Introduction}

The discovery of mild methods for the activation of C-F bonds is of high importance both from a fundamental point of view as well as for potential practical applications [1]. Specifically for aliphatic monofluorides, a number of transition metal-catalyzed methods [1-9] and transition-metal-free methodologies [1,1012] have been developed. In continuation with our interest in the activation of $\mathrm{C}-\mathrm{F}$ bonds [13-16], we have recently reported that it was possible to enable the use of fluoride as a leaving group in nucleophilic substitution reactions of activated alkyl fluorides through hydrogen bonding [17]. Particularly, water was used as the hydrogen bond donor and co-solvent. DFT calculations show that activation proceeds through stabilization of the transition-state structure by, amongst other things, hydrogen bonds between the fluorine atom and the water molecules, and not simple transition-state electrostatic stabilization by the solvent even though a mixture of polar solvent (iPrOH/ $\mathrm{H}_{2} \mathrm{O}$ in a $1: 1$ ratio) is used (Figure 1).

For its activating role in our system, water appeared to work mostly as a triad of spatially and geometrically well-defined 


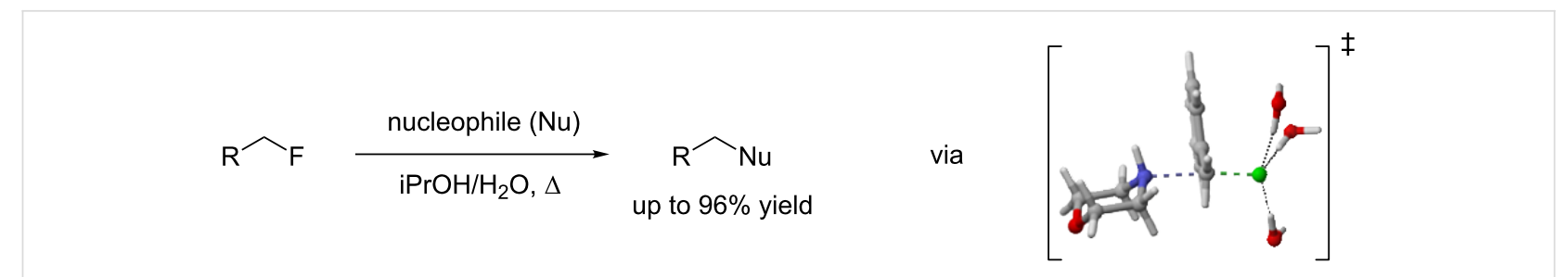

Figure 1: $S_{N} 2$ reaction of activated alkyl fluorides and calculated transition state for the reaction of morpholine with benzyl fluoride with three molecules of water.

hydrogen bond-donating moieties. We therefore wondered about what would happen if these three moieties (water molecules) were covalently linked together in the form of a triol, which could help the three $\mathrm{O}-\mathrm{H}$ functionalities to position themselves strategically around the three lone pairs of fluorine, which acts as a hydrogen bond acceptor [18-21] (Figure 2). Revoking the need to have five molecules (substrate, nucleophile and three water molecules) in a precise geometry could also enable a faster reaction with less activating agent, which means we could potentially use the triol as an additive rather than a solvent. Altogether, this strategy would represent a unique metal-free and unprecedented small-molecule-mediated activation of $\mathrm{C}-\mathrm{F}$ bonds.

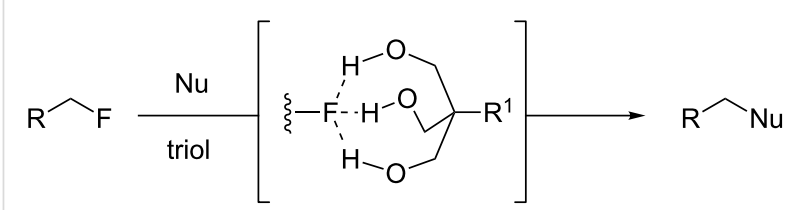

Figure 2: Proposed activation of C-F bonds mediated by a triol.

Herein, we report the feasibility of this concept for the amination of benzylic fluorides, activated alkyl fluorides [22], using 1,1,1-tris(hydroxymethyl)propane as the triol. Furthermore, optimization of the reaction conditions have revealed that the reaction was best run under highly concentrated conditions [23].

\section{Results and Discussion}

Our initial investigations were performed using 4-phenylbenzyl fluoride (1) [24] as the substrate and morpholine (3 equiv) as the nucleophile at $60{ }^{\circ} \mathrm{C}$ for $24 \mathrm{~h}$. Commercially available $1,1,1$ tris(hydroxymethyl)propane (2) was selected as the triol and was used in a slight excess (1.1 equiv) [25] relative to the substrate. Solvent screening was completed with and without added triol 2 in order to establish its effect on the reactivity and results are reported in Table 1. In water or alcoholic solvent without added triol, low to moderate conversions were observed (12-26\%). This was expected since these are all hydrogen bond-donor solvents $[17,26]$. A low but quantifiable increase in conversion is observed when $\mathbf{2}$ is added to these reactions, with the best result (35\%) being obtained in water (Table 1, entries $1-3)$. While the effect of the triol seems minimal, it is possible in these cases that $\mathbf{2}$, being both a hydrogen bond donor and acceptor, is engaged in a hydrogen bond network with the solvent, thus limiting its availability for the benzylic fluoride. Interestingly, switching to solvents with better acceptor than donor properties impeded the reaction [26]. Hence, the use of toluene (Table 1, entry 4), EtOAc (Table 1, entry 5), THF (Table 1, entry 6) and DMF (Table 1, entry 7) provided at best traces of the desired benzylic amine 3 . We speculate that the ability of the solvent to interact more strongly with the triol than would the substrate results in no reaction. Finally, "inert" solvents [26,27] such as hexane (Table 1 , entry 8 ) and $\mathrm{CH}_{2} \mathrm{Cl}_{2}$ (Table 1, entry 9) were investigated. In both cases, little reaction was observed without $\mathbf{2}$, and moderate conversions were obtained with 2 . In this instance, the solvent is unable to interact with either the triol or the substrate and the enhanced reactivity in the presence of the triol clearly demonstrates its activating role in this transformation. At this point, since solvents seemed more prone to hinder than help the reaction, we conducted an experiment without any solvent (Table 1, entry 10). Gratifyingly, a 54\% conversion was obtained in the presence of $\mathbf{2}$, while no conversion at all could be observed without the activating agent. It is important to mention for this entry that even if morpholine is the only liquid component at room temperature, a homogeneous solution is generated around $60{ }^{\circ} \mathrm{C}$ by the fusion of 1,1,1-tris(hydroxymethyl)propane (melting point $\left.56-58{ }^{\circ} \mathrm{C}\right)$.

Starting from our solvent-free conditions, which were providing the better results, we envisioned that further optimization was possible to improve the yield (Table 2). First, temperature had an important impact on conversion. Indeed, going from $60{ }^{\circ} \mathrm{C}$ (Table 2, entry 1 ) to $100^{\circ} \mathrm{C}$ (Table 2 , entry 3 ) smoothly effected a full conversion. It was also possible to reduce the amount of morpholine used from 3 equiv (Table 2, entry 3) to 2 equiv (Table 2, entry 5) without any impact on the conversion. However, lower amounts (Table 2, entries 6 and 7) resulted in decreased conversions. While a reasonable explanation for the requirement of excess amine would be its role in capturing the HF released during the reaction, control experiments did not 
Table 1: Initial screening
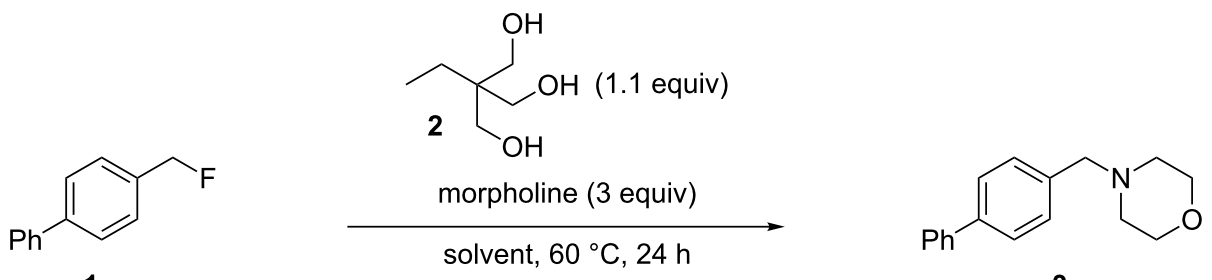

3

\begin{tabular}{llll}
\hline entry & solvent & \multicolumn{2}{c}{ conversion (\%) } \\
\cline { 3 - 3 } & & with 2 & without 2 \\
\hline 1 & $\mathrm{H}_{2} \mathrm{O}$ & 35 & 26 \\
2 & $\mathrm{EtOH}$ & 29 & 26 \\
3 & $\mathrm{iPrOH}$ & 16 & 12 \\
4 & toluene & $<3$ & $<3$ \\
5 & $\mathrm{AcOEt}$ & $<3$ & $<3$ \\
6 & $\mathrm{THF}$ & $<3$ & $<3$ \\
7 & $\mathrm{DMF}$ & $<3$ & $<3$ \\
8 & hexane & 21 & $<3$ \\
9 & $\mathrm{CH}_{2} \mathrm{Cl}_{2}$ & 26 & $<3$ \\
10 & - & 54 & $<3$ \\
\hline
\end{tabular}

a Determined by ${ }^{1} \mathrm{H}$ NMR analysis of the crude reaction mixture.

Table 2: Fine-tuning.

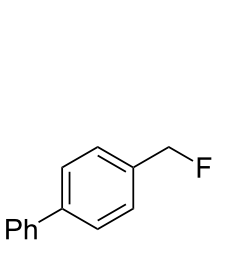

1
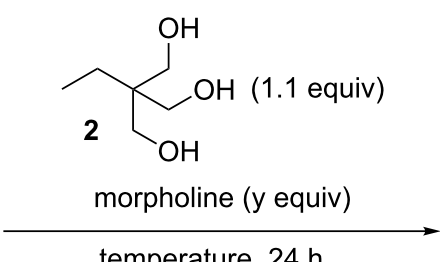

temperature, $24 \mathrm{~h}$

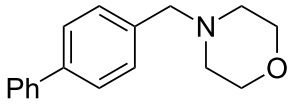

3

conversion $(\%)^{\mathrm{a}}$

\begin{tabular}{llll}
\hline entry & temperature & morpholine (equiv) & conversion (\%) \\
\hline 1 & 60 & 3 & 54 \\
2 & 80 & 3 & 90 \\
3 & 100 & 3 & $>97$ \\
4 & 100 & 2.5 & $>97$ \\
5 & 100 & 2 & $>97(86)^{\mathrm{b}}$ \\
6 & 100 & 1.5 & 91 \\
7 & 100 & 1 & 70 \\
$8^{\mathrm{c}}$ & 100 & 1 & 71 \\
$9^{\mathrm{d}}$ & 100 & 1 & 57 \\
$10^{\mathrm{e}}$ & 100 & 1 & 41 \\
\hline
\end{tabular}

aDetermined by ${ }^{1} \mathrm{H}$ NMR analysis of the crude reaction mixture. ${ }^{b} /$ solated yield. ${ }^{c} \mathrm{Et}_{3} \mathrm{~N}$ (1 equiv) was also added. ${ }^{\mathrm{d}} \mathrm{K}_{3} \mathrm{PO} \mathrm{O}_{4}(1$ equiv) was also added. ${ }^{\mathrm{e}} \mathrm{K}_{2} \mathrm{CO}_{3}$ (1 equiv) was also added.

support this proposal. For instance, running the reaction with 1 equiv of morpholine in the presence of 1 equiv of $\mathrm{Et}_{3} \mathrm{~N}$ provided the same conversion (Table 2, entry 8) while using inorganic bases ( 1 equiv of either $\mathrm{K}_{3} \mathrm{PO}_{4}$ or $\mathrm{K}_{2} \mathrm{CO}_{3}$ ) gave lower conversions (Table 2, entries 9 and 10). The reasons for such observations are unclear at present. Nonetheless, conditions presented in entry 5 were chosen for evaluation of the scope. 
As shown in Table 3, reactivity is not limited to benzylic fluoride 1 and morpholine. A range of secondary amines can be used, as cyclic (Table 3, entries 1, 2, 5, 6, 8 and 11), acylic (Table 3, entries 3, 4, 9 and 10) and aromatic (Table 3, entry 7) $\mathrm{N}$-nucleophiles all provide good isolated yields. In the case of $\mathrm{N}$-methylaminoethanol, complete selectivity was observed for $N$-benzylation (Table 3, entries 4 and 10). The reaction also tolerates simple electronic variations on the benzylic fluoride, as the 4-phenyl group can be exchanged for a 4-bromo (Table 3, entries 5-7), 4-tert-butyl (Table 3, entries 8-10) or 3-methoxy group (Table 3, entry 11 ) with only minor impact on the conversion. Overall, conversion into the desired product was superior to $90 \%$ for all entries, and only the purification step proved detrimental to the isolated yields. This is further demonstrated by the reaction run at a greater scale which facilitated the purification and resulted in a higher isolated yield (Table 3 , entry 1 ).

Table 3: Substrate scope

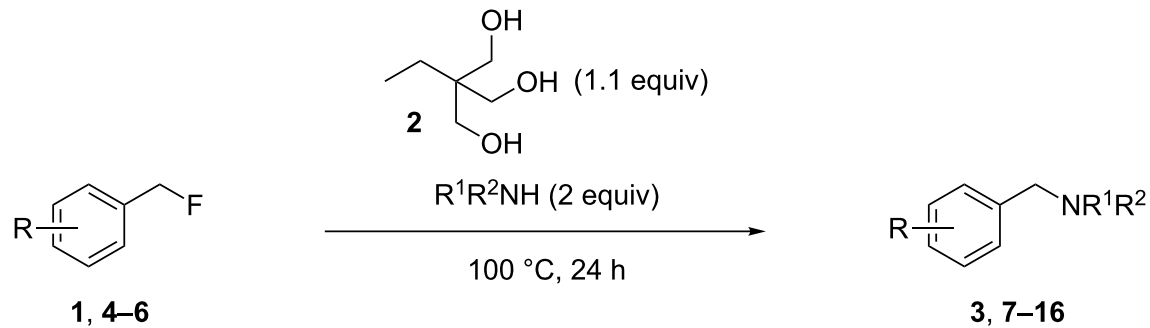

\begin{tabular}{|c|c|c|c|c|}
\hline entry & benzyl fluoride & $\mathrm{R}^{1} \mathrm{R}^{2} \mathrm{NH}$ & product & yield $(\%)^{a}$ \\
\hline 1 & 1 & & 3 & $86(97)^{b}$ \\
\hline 2 & 1 & & 7 & 79 \\
\hline 3 & 1 & & 8 & 83 \\
\hline 4 & 1 & & 9 & $77^{c}$ \\
\hline 5 & 4 & & 10 & 72 \\
\hline 6 & 4 & & 11 & 64 \\
\hline 7 & 4 & & 12 & 56 \\
\hline 8 & 5 & & 13 & 86 \\
\hline
\end{tabular}


Table 3: Substrate scope. (continued)

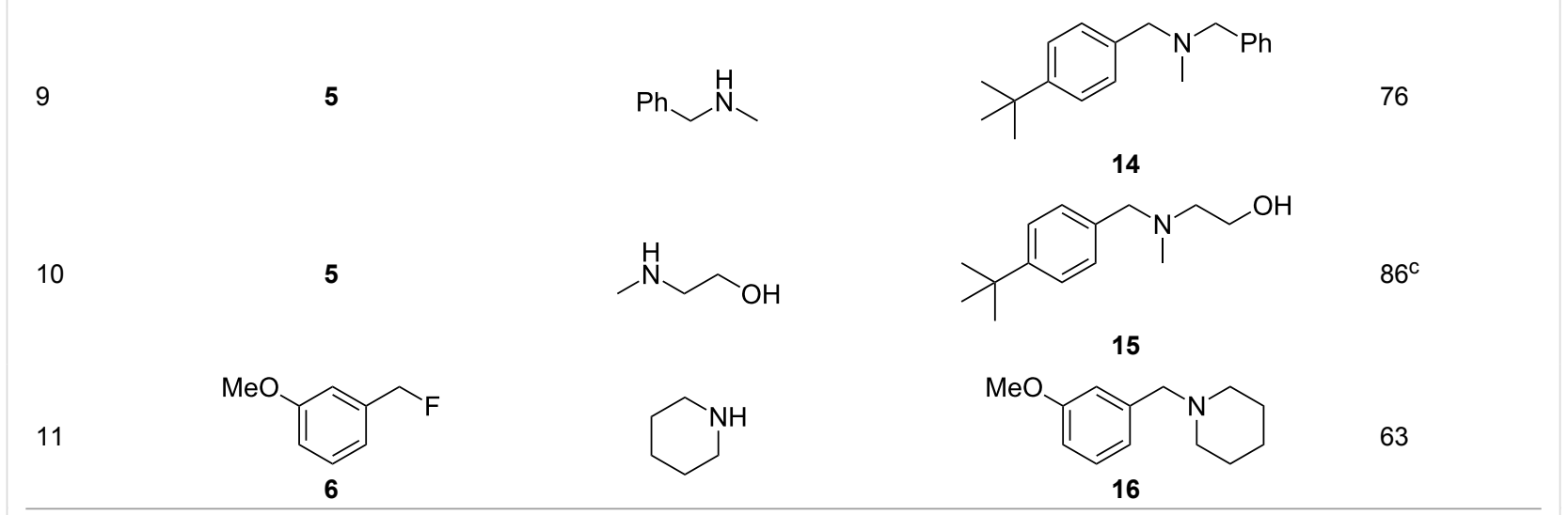

alsolated yield for reaction on $0.16 \mathrm{mmol}$ scale. ${ }^{b}$ Isolated yield for reaction on $0.81 \mathrm{mmol}$ scale. ${ }^{\mathrm{N}}$ No product of O-benzylation could be detected by ${ }^{1} \mathrm{H}$ NMR on the crude reaction mixture.

Reactions of secondary benzylic fluorides were unfortunately untractable, and primary aliphatic amines (i.e. $n$-butylamine) generated a mixture of inseparable mono- and dibenzylation products (see Supporting Information File 1 for details).

\section{Conclusion}

In summary, we have described that according to our previous proposed mechanism for the hydrogen bond-promoted $\mathrm{C}-\mathrm{F}$ bond activation [17], simultaneous coordination of the three lone pairs of fluorine by a triol (e.g. 2) permits the nucleophilic substitution of benzylic fluorides by amines under neutral and solvent-free conditions. To further support this hypothesis, solvent properties concerning their hydrogen bond acidity or basicity correlate well with the experimental evidence of reactivity. Investigations concerning the reaction mechanism and precise role of the three hydroxy groups of $\mathbf{2}$ for the reaction are currently underway in our laboratory.

\section{Supporting Information}

\section{Supporting Information File 1}

General methods, synthetic procedures, ${ }^{1} \mathrm{H}$ NMR spectra for known compounds and full characterization of all new compounds.

[http://www.beilstein-journals.org/bjoc/content/ supplementary/1860-5397-9-283-S1.pdf]

\section{Acknowledgements}

This work was supported by the Canada Research Chair Program, the Natural Sciences and Engineering Research Council of Canada, the Canada Foundation for Innovation, the FRQNT Centre in Green Chemistry and Catalysis (CGCC), the
FQRNT Network for Research on Protein Function, Structure, and Engineering (PROTEO) and the Université Laval.

\section{References}

1. Amii, H.; Uneyama, K. Chem. Rev. 2009, 109, 2119-2183. doi:10.1021/cr800388c

2. Ahrens, M.; Scholz, G.; Braun, T.; Kemnitz, E. Angew. Chem., Int. Ed. 2013, 52, 5328-5332. doi:10.1002/anie.201300608

3. Janjetovic, M.; Träff, A. M.; Ankner, T.; Wettergren, J.; Hilmersson, G. Chem. Commun. 2013, 49, 1826-1828. doi:10.1039/c3cc37828d

4. Azhakar, R.; Roesky, H. W.; Wolf, H.; Stalke, D. Chem. Commun. 2013, 49, 1841-1843. doi:10.1039/c3cc38669d

5. Haufe, G.; Suzuki, S.; Yasui, H.; Terada, C.; Kitayama, T.; Shiro, M.; Shibata, N. Angew. Chem., Int. Ed. 2012, 51, 12275-12279. doi:10.1002/anie.201207304

6. Caputo, C. B.; Stephan, D. W. Organometallics 2012, 31, 27-30. doi:10.1021/om200885c

7. Douvris, C.; Nagaraja, C. M.; Chen, C.-H.; Foxman, B. M.; Ozerov, O. V. J. Am. Chem. Soc. 2010, 132, 4946-4953. doi:10.1021/ja100605m

8. Zhang, L.; Zhang, W.; Liu, J.; Hu, J. J. Org. Chem. 2009, 74, 2850-2853. doi:10.1021/jo802819p

9. Matsubara, K.; Ishibashi, T.; Koga, Y. Org. Lett. 2009, 11, 1765-1768. doi:10.1021/OI900208n

10. Blessley, G.; Holden, P.; Walker, M.; Brown, J. M.; Gouverneur, V. Org. Lett. 2012, 14, 2754-2757. doi:10.1021/ol300977f

11. Choi, J.; Wang, D. Y.; Kundu, S.; Choliy, Y.; Emge, T. J.; Krogh-Jespersen, K.; Goldman, A. S. Science 2011, 332, 1545-1548. doi:10.1126/science.1200514

12. Hazari, A.; Gouverneur, V.; Brown, J. M. Angew. Chem., Int. Ed. 2009, 48, 1296-1299. doi:10.1002/anie.200804310

13. Pigeon, X.; Bergeron, M.; Barabé, F.; Dubé, P.; Frost, H. N.; Paquin, J.-F. Angew. Chem., Int. Ed. 2010, 49, 1123-1127. doi:10.1002/anie.200904747

14. Paquin, J.-F. Synlett 2011, 289-293. doi:10.1055/s-0030-1259333

15. Bergeron, M.; Johnson, T.; Paquin, J.-F. Angew. Chem., Int. Ed. 2011, 50, 11112-11116. doi:10.1002/anie.201105138 
16. Bergeron, M.; Guyader, D.; Paquin, J.-F. Org. Lett. 2012, 14, 5888-5891. doi:10.1021/ol302802r

17. Champagne, P. A.; Pomarole, J.; Thérien, M.-Ė.; Benhassine, Y.; Beaulieu, S.; Legault, C. Y.; Paquin, J.-F. Org. Lett. 2013, 15, 2210-2213. doi:10.1021/ol400765a

18. Schneider, H.-J. Chem. Sci. 2012, 3, 1381-1394. doi:10.1039/C2SC00764A

19. Giuffredi, G. T.; Gouverneur, V.; Bernet, B. Angew. Chem., Int. Ed. 2013, 52, 10524-10528. doi:10.1002/anie.201303766

20. Graton, J.; Wang, Z.; Brossard, A.-M.; Gonçalves Monteiro, D. LeQuestel, J.-Y.; Linclau, B. Angew. Chem., Int. Ed. 2012, 51, 6176-6180. doi:10.1002/anie.201202059

21. Scerba, M. T.; Leavitt, C. M.; Diener, M. E.; DeBlase, A. F.; Guasco, T. L.; Siegler, M. A.; Bair, N.; Johnson, M. A.; Lectka, T. J. Org. Chem. 2011, 76, 7975-7984. doi:10.1021/jo2015328

22. Bordwell, F. G.; Brannen, W. T. J. Am. Chem. Soc. 1964, 86, 4645-4650. doi:10.1021/ja01075a025

23. Walsh, P. J.; Li, H.; Anaya de Parrodi, C. Chem. Rev. 2007, 107, 2503-2545. doi:10.1021/cr0509556

24. Benzylic fluoride 1 is prepared in two steps with an overall yield of $64 \%$ from commercially available 4-biphenylmethanol, see reference [17] for details.

25. Reaction proceeded equally well with 2 equiv of the triol.

26. Kamlet, M. J.; Abboud, J. L. M.; Abraham, M. H.; Taft, R. W. J. Org. Chem. 1983, 48, 2877-2887. doi:10.1021/jo00165a018

27. Inert solvent refers here to the fact that it is neither a hydrogen-bond donor solvent nor a hydrogen-bond acceptor solvent.

\section{License and Terms}

This is an Open Access article under the terms of the Creative Commons Attribution License (http://creativecommons.org/licenses/by/2.0), which permits unrestricted use, distribution, and reproduction in any medium, provided the original work is properly cited.

The license is subject to the Beilstein Journal of Organic Chemistry terms and conditions:

(http://www.beilstein-journals.org/bjoc)

The definitive version of this article is the electronic one which can be found at: $\underline{\text { doi: } 10.3762 / \text { bjoc. } 9.283}$ 